\title{
EL EPISODIO DE MARCELA Y GRISÓSTOMO EN EL CONTEXTO DEL QUIJOTE
}

\author{
Eugenia Fosalba \\ Universidad de Gerona
}

\begin{abstract}
This study attempts to recollect the original place in which the story of Marcela and Grisóstomo was located in the first version of the Quixote, and presents the entire interpretation of the passage while recalling this original context. The main scenes of the story are revised according to each one's critical tradition, but primarily according to the author's wish to realistically rewrite a pastoral episode, a wish of realism which is - surprisingly enough - often reinforced by the deepest bucolic sources. A quick glance at the very first bilingual translation in France (1609) of the episode, and its influence on another later version of 1715 , offers more information about the difficulties of Cervantes' reception in Europe, and of the original values of the Spanish text, lost in the process.
\end{abstract}

El primer texto que Cervantes ofrece a la imprenta para darse a conocer como escritor es la Galatea, obra pastoril de trama extraordinariamente enrevesada por sus atomizados relatos secundarios, dotada además de un ambicioso elenco de poemas interpolados. Cuando ya anciano y enfermo se despide con inimitable y conmovedora gracia de sus lectores, confiesa al Conde de Lemos en los preliminares a la edición póstuma de su Persiles que si el cielo le diese vida culminaría esa lejana novela de debutante. Era el 19 de abril de 1616, y le quedaban escasas horas en este mundo. Había llovido mucho desde 1585, y sin embargo, Cervantes seguía, genio y figura, manteniendo en el lecho de muerte ese afán tan suyo de corregir a ritroso, sin posibilidad de modificar lo ya escrito. ${ }^{1}$ Porque las críticas que había vertido sobre el universo almibarado de los pastores novelescos en el Coloquio de los perros dan indicio de qué era en verdad lo que le había quedado en el tintero: más que anudar los cabos todavía sueltos de la trama para siempre abierta de la Galatea, barruntaba a buen seguro otra versión de los rústicos virgilianos, más cercana al mundo cotidiano y por tanto verosímil. El episodio que ocupa los capítulos 11 a 14 del Quijote de 1605 fue el único y parcial cumplimiento que pudo dar a ese deseo. ${ }^{2}$ Como ya demostró Geoffrey Stagg pronto hará medio siglo, esa digresión narrativa fue desgajada con prisas del capítulo 25, donde don Quijote y Sancho se hallaban en plena Sierra Morena. Su paisaje de rasgos montañosos, más afin que el del llano al carácter arisco e indomable de Marcela, se mantenía en azarosos jirones de frases que resultaban fuera de contexto en

\footnotetext{
${ }^{1}$ Así entiende Francisco Rico a don Quijote en la segunda parte: “...una corrección a ritroso que el novelista efectúa con exquisita discreción (...). Es un Olvidábaseme de decir... tácito, un complemento de importancia añadido cuando ya ni se puede ni se quiere volver atrás sobre lo escrito, sobre lo impreso", en "Las dos interpretaciones del Quijote", Breve biblioteca de autores españoles, Barcelona, Seix Barral, 1991, p. 160.

${ }^{2}$ Véase A.K. Forcione, "Marcela and Grisóstomo and the Consummation of La Galatea", en Cervantes: Essays for L.A. Murillo, Newark, Juan de la Cuesta, 1987, pp. 47-62. Pilar García Carcedo, La Arcadia en el Quijote. Originalidad en el tratamiento de los seis episodios pastoriles, Bilbao, Ediciones Beitia, 1996.
} 
plena meseta castellana. ${ }^{3}$ No es casualidad que Cervantes hubiera situado en principio al coro de cabreros en un telón de fondo más convincente que el manoseado locus amoenus de indeleble factura literaria, pues era su voluntad reescribir la socorrida historia del pastor no correspondido con buenas dosis de realismo.

Durante la redacción de la primera parte del Quijote, Cervantes iba cambiando el concepto que tenía de los personajes, los narradores, y la estructura episódica de la novela que estaba escribiendo. Cualquier acercamiento al texto de 1605 debe tener presente su carácter mutante y no va a dejar de ser así con respecto a las circunstancias que rodean la aparición del caso de Marcela y Grisóstomo. Ni mucho menos. No olvidemos, además, que ese brusco cambio de planes en la ubicación del episodio pastoril dio lugar nada menos que a la volatilización del asno de Sancho, sonado desaguisado del que se burlaría Lope en su comedia Amar sin saber a quién ${ }^{4}$. ¿Por qué fue originalmente a la altura del capítulo 25 cuando decidió el variopinto narrador del Quijote adentrarse en una historia de pastores enamorados y desamorados? Creo que la titubeante estructura narrativa del Quijote de 1605 puede proporcionar la respuesta. Cuando Cervantes empieza a desconfiar del grado de interés que puedan seguir teniendo para el lector las tundas de palos que Don Quijote y su escudero reciben una y otra vez a causa de las alucinaciones provocadas por la fascinación literaria del primero, determina dar un valiente golpe de timón al modelo narrativo que proporciona la ristra de parodias caballerescas, para empezar a insertar relatos intercalados que ofrezcan como entretenimiento un abanico variado de géneros novelescos (aparte de la historia pastoril que nos ocupa, la novela sentimental en la historia de Cardenio, la novela cortesana o psicológica en la del Curioso impertinente, la novela de aventuras en el relato del cautivo) puesto el objetivo en aliviar la atención concentrada en la inmortal pareja. ¡Qué lejos estaba entonces Cervantes de adivinar la inmensa e inmediata aceptación que ambos obtendrían! Y al parecer, en España, no pocos lectores se lo reprocharon, pues como es bien sabido pidió toda suerte de excusas y se cuidó muy mucho de volver a repetir la experiencia en 1615. En su norte se perfiló de nuevo la Diana, modelo constante de su obra completa, una de cuyas manifestaciones sería la tendencia al uso de relatos secundarios entreverados con la trama principal, ya presente de forma muy acusada en la Galatea sobre el cañamazo de una trama bizantina que, como ha demostrado Montero, Cervantes supo intuir en los preparativos durmientes de la Diana - a la espera de una futura secuela truncada por la

\footnotetext{
${ }^{3}$ De todas maneras conviene no exagerar el carácter escarpado de la orografía de Sierra Morena, quizá poco presente para el crítico anglosajón, fallecido recientemente (10 de Noviembre de 2004). Véase su "Revisión in Don Quixote, Part I», en Hispanic Studies in Honour of I. González Llubera, Oxford, Dolphin Books, 1959, pp. $347-66$.

${ }^{4}$ El robo del asno de Sancho sucedía en plena Sierra Morena y el ladrón era Ginés del Pasamonte, quien a la altura de la nueva ubicación adelantada del episodio de Marcela y Grisóstomo todavía no había comparecido en la novela. La desaparición del pasaje en que se describe el robo, mientras Don Quijote y Sancho duermen rendidos rodeados de los cabreros se debió en la precipitada primera edición a que Cervantes extrajo el pasaje del episodio pastoril y después olvidó añadirlo en el lugar adecuado del capítulo 25; su ubicación errónea en el capítulo 23 de la segunda edición, impresa pocos meses después de la princeps, aumentó todavía más la confusión, que Cervantes trató de disimular en el Quijote de 1615 sacudiéndose las culpas, pues "el historiador se engañó o sería descuido del impresor". Véanse las explicaciones y bibliografía que ofrece Martín de Riquer en su edición de Planeta, en la primera nota al capítulo 23 .
} 
muerte prematura de Montemayor- ; $^{5}$ propensión al arabesco jalonado por episodios menores que sin contención volvería a invadir el Persiles más de treinta años después. ${ }^{6}$

Este cambio de rumbo se imprime a la altura del capítulo 23, cuando don Quijote y Sancho abandonan el paisaje que hasta entonces -de acuerdo a la primitiva redacción- era el del camino sobre un campo abierto, llano y ondulado, solo interrumpido por el galvanizador y teatral espacio interior de la venta, y algún bosquecillo, como el que da pie a la hilarante aventura de los batanes. El adentrarse ahora en la sierra huyendo de la Santa Hermandad se propone como un cambio; cambio que no sucede sin el aviso previo y claro de su autor: "....se entraron por una parte de Sierra Morena, que allí junto estaba, llevando Sancho intención de atravesarla toda e ir a salir al Viso o a Almodóvar del Campo." No sólo se advierte al lector del nuevo decorado, sino del efecto que éste surte en el protagonista, pues así “como entró don Quijote por aquellas montañas, se le alegró el corazón, pareciéndole aquellos lugares acomodados para las aventuras que buscaba." La variedad que ofrece el espectáculo natural irregular de la sierra estimula la sedienta imaginación del hidalgo manchego pues contribuye a crear una atmósfera azarosa e intrincada que rompe con las casualidades anteriores, ordenadas en una serie excesivamente lineal. El horizonte ya no está a lo lejos en polvorientas figuras que, lentas, se agrandan a medida que se van acercando y pueden distinguirse con mayor claridad, sino que la aventura puede presentarse bajo cualquier perspectiva, en el momento más inesperado y de la forma más insospechada.

Sancho prosigue tras su amo, sentado a la mujeriega sobre su mulo, entretenidísimo sacando de su costal y embaulando su panza, y "no se le diera por hallar otra aventura, entre tanto iba de aquella manera, un ardite". Pero en esto "alzó los ojos", y así vio a su amo que estaba parado, "procurando con la punta del lanzón alzar no sé que bulto que estaba caído en el suelo": la curiosidad puede con él y para averiguar qué regalo les ha deparado la providencia, desmonta en un abrir y cerrar de ojos de su jumento dejando a un lado las sobras de viandas de los frailes, y descubre con don Quijote y el lector que el bulto es un misterioso cojín de montar y una maleta, ambos en estado de semiputrefacción. Como en la mejor tradición decimonónica de Sir Arthur Conan Doyle, la pareja se detendrá en la cuidadosa observación de las prendas que contiene la desvencijada maleta: cuatro impecables camisas de delgada holanda, un pañizuelo con un "buen montoncillo de escudos de oro", y un soneto amoroso, con una misiva cuya lectura y análisis detectivesco proporcionará -además de la excusa para interpolarla a continuación- una conversación concentrada en la adivinación de la enigmática identidad de su dueño. ${ }^{7} \mathrm{La}$ aparición de Cardenio no tarda en ir preparando respuestas a las numerosas preguntas que dan vueltas en las cabezas de don Quijote y Sancho, y sucede de la misma forma impensada: el plano en picado que había descubierto la maleta desde el extremo del lanzón de don Quijote se transforma, de pronto, en un contrapicado cuando el caballero "vio por cima de una

\footnotetext{
5 “¿Mató Montemayor a Celia? La historia de Felismena a la luz de sus fuentes”, Hommage à Robert Jammes, Toulouse, Université de Toulouse-Le Mirail, 1994, pp. 865-874

${ }^{6}$ Jorge García López ha estudiado en su admirable edición de las Novelas ejemplares en Crítica, 2001, la preferencia de Cervantes por el relato breve, que explicaría su reunión en una edición antológica a la altura de 1613.

${ }^{7}$ Alberto Blecua ya advirtió en una reciente conferencia que el peculiar intercambio verbal de deducciones entre Sherlock Holmes y Watson tiene a buen seguro un primer bosquejo aquí.
} 
montañuela que delante de los ojos se le ofrecía iba saltando un hombre de risco en risco y de mata en mata con estraña ligereza."

Tras dar con la mula muerta, tendrán ocasión de intercambiar unas palabras con un cabrero -de los mismos que forman el coro de la historia de Marcela-, quien les dará nueva información, aunque incompleta, sobre el asilvestrado muchacho. La aparición del propio "Roto de la Mala Figura" ofrecerá una nueva perspectiva a la historia amorosa de Cardenio en el capítulo siguiente (24); este diálogo, junto a la imitación quijotesca de Beltenebros poco después del comienzo del siguiente (25), constituirán el contexto narrativo, el antes y el después, en cuyo centro situaba Stagg la cicatriz de la extracción del relato, donde debería irrumpir la historia de Marcela. "Cortina de agua" fue la expresión que empleó: hilando más fino la situó poco después de dar comienzo el actual capítulo 25 , justo después del enfado quijotesco por las ristras de refranes de Sancho e inmediatamente antes de las protestas del mismo Sancho por andar perdidos en esas montañas, quejoso quizá porque reclamaba algo del protagonismo perdido. Por momentos, la participación de don Quijote ha dejado de ser de primer orden, porque para hacer un hueco al salvaje divisado a lo lejos, que no es más que el "Roto de la Mala Figura" que se aparece después, y a los amores y desamores de Marcela y Grisóstomo en último lugar, ha tenido que pasar a un segundo plano y quedar poco menos que de hilo conductor de peripecias ajenas -salpicadas, eso sí, por sus jugosos comentarios, discursos, y dimes y diretes con Sancho.

Decíamos que al dar comienzo la imitación del modelo estrutural de la Diana Cervantes escogía adentrar a sus protagonistas en un escenario menos lineal, más lleno de tropiezos y azares, más agreste también y acorde entonces con un entorno menos dulce que un locus amoenus estereotipado. Sin embargo, el verdadero paisaje arcádico, donde Virgilio situaba a los pastores maestros del canto ("Tristis at ille: 'Tamen cantabitis, Arcades' inquit / "montibus haec uostris, soli cantare periti / Arcades", Buc. X, 31-32), era en su origen el centro a su vez montañoso y agreste del Peloponeso, cuya naturaleza severa y ruda de cordilleras angostas invitaba a sus moradores, como explicaba el historiador arcadio, Polibio, en el libro IV de sus Historias, a templarla y dulcificarla con el canto ${ }^{8}$. Se entiende mejor así la preferencia de Cervantes por el paisaje implícito de Sierra Morena para introducir una región arcádica en el Quijote. No será la única vez que recurre a una quintaesencia del bucolismo para conseguir crear el efecto de verosimilitud mientras se halla bajo la batuta de la novela inaugurada por Montemayor.

Esa aparente búsqueda de realismo le impulsa a poner en boca de don Quijote el discurso sobre la Edad de Oro, que tiene aquí una función inaugural con respecto a las andanzas entre rústicos, y que el hidalgo pronuncia con la tripa llena, de acuerdo con la nueva estética pastoril que ahora propone Cervantes y en desacuerdo con el hidalgo desganado al que nos tenía acostumbrados. Todo cuanto ahora le rodea le lleva a recordar con nostalgia la antigua y verdadera sencillez, y no por casualidad -como acabamos de

\footnotetext{
${ }^{8}$ Panofsky menciona también la Arcadia de Polibio como un lugar desapacible y rocoso, aunque no explicita su carácter montañoso, en su fundamental estudio "Et in Arcadia Ego: Poussin y la tradición elegíaca", El significado en las artes visuales, Madrid, Alianza, 1979, pp. 323-348. Fueron Virgilio y Ovidio quienes recuperaron el austero paisaje de Arcadia, pues el griego Teócrito prefirió lógicamente situar su pastoral en el paisaje blando de la Sicilia de entonces.
} 
ver- incluso en el paisaje escarpado hay cierta réplica de esas "quiebras de las peñas" recordadas en su adornado discurso, en lo hueco de cuyos árboles "formaban su república las solícitas y discretas abejas". En preparación del primer bosquejo de Marcela, que Cervantes pondrá en boca de un recién llegado, don Quijote alude a la auténtica simplicidad de las pastoras de antaño, tan acorde con el tosco agasajo que ahora le ofrecen los cabreros:

Entonces sí que andaban las simples y hermosas zagalejas de valle en valle y de otero en otero, en trenza y en cabello, sin más vestidos de aquellos que eran menester para cubrir honestamente lo que la honestidad quiere y ha querido siempre que se cubra, y no eran sus adornos de los que ahora se usan, a quien la púrpura de Tiro y la de por tantos modos martirizada seda encarecen, si no de algunas hojas verdes de lampazos y yedra entretejidas, con lo que quizá iban tan pomposas y compuestas como van agora nuestras cortesanas con las raras y peregrinas invenciones [por "disfraces"] que la curiosidad ociosa les ha mostrado. (El subrayado es mío)

Y en efecto, poco después, al dar comienzo el capítulo siguiente, el mozo encargado de traer a los cabreros las provisiones ofrece el primer retrato de nuestra protagonista, "aquella endiablada Marcela, hija de Guillermo el rico"; rica heredera que no renuncia a la fantasía -como las cortesanas del discurso quijotesco- de ataviarse con raras y peregrinas invenciones: Marcela es "aquella que se anda en hábito de pastora por esos andurriales" (I, 12), añade con tono despectivo el rústico mozuelo. Nótese el contraste entre la extravagancia del ocioso antojo y los lugares polvorientos y pedestres que evoca el sustantivo coloquial "andurriales". El mismo cabrero nos explica pocas líneas más abajo la voluntad de Grisóstomo de ser enterrado "en el campo, como si fuera moro, y que sea al pie de una peña donde está la fuente del alcornoque," donde al parecer vio por vez primera a Marcela. "A todo lo cual responde aquel su gran amigo Ambrosio, el estudiante, que también se vistió de pastor como él, que se ha de cumplir todo, sin faltar nada..." Ambos detalles deben ser muy tenidos en cuenta al analizar el episodio: el capricho por disfrazarse fue una costumbre entre la nobleza más encumbrada, ya en tiempos de Felipe $\mathrm{II}^{9}$, pero sobre todo en los reinados de sus descendientes - menos austeros-, hasta convertirse en una verdadera epidemia de la que se quejaba amargamente Lope de Vega en su epistolario: la manía de disfrazarse como actores, ${ }^{10}$ y más y mejor si era para interpretar una égloga áulica ataviados con todo lujo al modo de aristocráticos pastores, como en la versallesca Arcadia con la que Don Quijote tropieza literalmente en el volumen de 1615 (II, 58) ${ }^{11}$. En Francia, cuya imitación de la Diana daría frutos tan queridos de su propia aristocracia como

\footnotetext{
${ }^{9}$ Véase la escenificación hacia 1586 de La fábula de Dafne por parte de damiselas aristócratas, en E. Fosalba, "Impronta italiana en varias églogas dramáticas del Siglo de Oro: Juan del Encina, Juan Sánchez Coello (?) y Lope de Vega", Anuario Lope de Vega, VIII (2002), pp. 81-120.

10 “...y el mayor temor desto es yr a servir a un linage de mujeres esquisito, donde quieren amar, vestir, y hablar fuera de los limites de la naturaleza, siendo en las cosas della como en las otras. ¡Bueno estuviera el pobre clérigo, poeta eunuco, a la puerta de un serrallo de mujeres, angeles en la gerarquia, damas en los melindres y monjas en los deseos!, en Agustín González de Amezúa, ed. Epistolario de Lope de Vega Carpio, Madrid, Gráficas Ultra, 1935-43, t. III, p. 322. Citado por Teresa Ferrer Valls en su artículo "Vestuario teatral y espectáculo cortesano en el Siglo de Oro", M. de los Reyes Peña, ed. El vestuario en el teatro español del Siglo de Oro. Cuadernos de teatro clásico, 13-14 (2000), pp. 63-84.

${ }^{11}$ Véase mi estudio sobre éste y otros aspectos relacionados con la égloga representable en la novela en "Egloga mixta y égloga dramática en la creación de la novela pastoril”, La Egloga, IV Encuentro sobre Poesía del Siglo de Oro, Sevilla, Universidad de Sevilla, 2002, pp. 121-182.
} 
L'Astrée, y un reguero nada despreciable de obras teatrales inspiradas en las anécdotas de la novela española, se prolongará hasta María Antonieta el deseo de hacer "real" esa veleidad. Vale deducir entonces que en tiempos de Cervantes no era ninguna ocurrencia excéntrica presentar de esta guisa a una rica terrateniente o a un estudiante de Salamanca, "hijodalgo rico", "vecino de un lugar que estaba en aquellas sierras".

Aunque la forma de narrar busque la creación de una atmósfera azarosa, lo cierto es que la presentación de la historia del desdichado Grisóstomo dista mucho de ser fruto de la inspiración a veces caprichosa de Cervantes. Asistimos a continuación a la narratio bastante objetiva del caso de la "melindrosa Marcela" de parte del cabrero Pedro (cap. 12), y más adelante, después de la larga conversación del hidalgo con Vivaldo sobre la vigencia de la andante caballería, se formula la acusación (cap. 13) ${ }^{12}$ por parte de Ambrosio, estudiante de exquisita elocuencia disfrazado de pastor, quien en pleno elogio fúnebre de Grisóstomo, presenta en una serie de endecasílabos y octosílabos encadenados a la bella pastora como culpable del suicidio de su amigo. Según su versión de los hechos, Grisóstomo "quiso bien, fue aborrecido, adoró, fue desdeñado; rogó a una fiera, importunó a un mármol, corrió tras el viento, dio voces a la soledad, sirvió a la ingratitud, de quien alcanzó como premio ser despojos de la muerte en la mitad de la carrera de su vida". Donde no por casualidad, y quizás para subrayar ahora el subjetivismo de su perspectiva, se engarzan ecos, no sólo dantescos y garcilasianos, ${ }^{13}$ sino también de la Canción de Silvano, pastor nunca correspondido, muy quejoso en el libro primero de la Diana: "Amador soy, mas nunca fui amado; / quise bien y querré, no soy querido". ${ }^{14} \mathrm{Al}$ final, la acusada tomará cartas en el asunto (cap. 13), y demostrará con su culto y preciso lenguaje que, en efecto, no es una auténtica pastora, para erigirse en su propia letrada defensora, y pronunciar un impecable discurso judicial y demostrativo que pone el broche a esta historia secundaria. Toda la presentación del relato, podemos deducir así, está organizada para justificar este brillante ejercicio de oratoria feminista. La estructura de su intervención, como ha recordado Alberto Blecua en más de una ocasión, demuestra la influencia que en la formación de Cervantes, como en cualquier persona de cultura media y superior en el Siglo de Oro, tuvieron los progymnasmata o discursos breves: el exordio en el comienzo, cuando se propone el asunto que se va a tratar: “... dar a entender cuán fuera de razón van todos aquellos que de sus penas y de la muerte de Grisóstomo me culpan", y su desarrollo con toda suerte de tópicos, como llamar la atención del público, “....ruego a todos que me estéis atentos", así como prometer ser breve o elogiar al público para captar su benevolencia: “...que no será menester mucho tiempo ni gastar muchas palabras para persuadir una verdad a los discretos”. Marcela se arma de la más fina artillería dialéctica, sin dejar de valerse de toda suerte de argumentos de corte silogístico ("todo lo hermoso es amable, mas no alcanzo que, por razón de ser amado, esté obligado lo que es amado por hermoso a amar a quien le ama"), entimemas (o silogismos abreviados: "si yo le entretuviera, fuera falsa") y epiqueremas (alguna de cuyas premisas va acompañada de pruebas: "si los deseos se

\footnotetext{
${ }^{12}$ Martha García analizaba muy recientemente los distintos niveles de ficción en la narración de los hechos, que en las primeras versiones aportan más opiniones que acontecimientos, en "Marcela: ¿defendida o defensora? Un tribunal cervantino", Anuario de estudios cervantinos, I (2004), pp. 165-174.

${ }^{13}$ Véase la anotación de la edición de Crítica, 1998, p. 144.

${ }^{14}$ Y más adelante: “Quejarme yo de amor es excusado; / pintá en el agua o dá voces al viento...”. Cito por la edición de La Diana de Juan Montero en Crítica, 1996, p. 20.
} 
sustentan con esperanzas, no habiendo yo dado alguna a Grisóstomo, ni a otro alguno el fin de ninguno dellos, bien se puede decir que antes le mató su porfía que mi crueldad"), para empezar su argumentación por rebatir las razones de sus adversarios; su estrategia consiste en pasar del caso personal (quaestio finita) al general (la quaestio infinita de la hermosura). ${ }^{15}$

No es mi intención añadirme aquí a la larga y polémica discusión sobre el suicidio de Grisóstomo que quizás ha monopolizado con exageración los estudios sobre este interludio pastoril: una vez más fue Américo Castro con su prosa intuitiva y sugerente quien abrió fuego al afirmar con flagrante anacronismo que Cervantes solo se atrevió a dejar claro el suicidio en la Canción deseperada de Grisóstomo y difuminó en la prosa tal certeza pues "sabía que la casi totalidad de los lectores se saltan los versos de las novelas." Al parecer quería pasar sobre la idea del suicidio como "sobre ascuas" para satisfacer así a su público y a su tiempo, de acuerdo con el espíritu postridentino. ${ }^{16}$ Avalle-Arce publicó una nota en 1957 en donde perfilaba algunas ideas barajadas por Castro; aceptaba que el suicidio era poco menos que un "escollo insalvable en la España de la segunda mitad del siglo XVI: la Reforma católica identifica el suicidio con la condenación del alma", y se detenía en otro supuesto impedimento "estético-literario": "El suicidio, como todo acto de sangre, no tiene cabida en el orbe de lo pastoril, que es donde se han refugiado Grisóstomo y Marcela", y para sustentar esta sorprendente afirmación, citaba las Anotaciones de Herrera: "La materia desta poesía es las cosas i obras de los pastores, mayormente sus amores, pero simples i sin daño, no funestos, con rabia de celos, no manchados con adulterios." Pero Herrera debía estar defendiendo aquí su propia idea, estilizada, de la égloga, género que pretendía dignificar, junto a otras especies de la lírica como la canción o la elegía, que entendía se decantaban por lo general hacia el tema amoroso, y cuyo estilo apropiado debería ser el mediano, liberado de rusticismos o vulgaridades que no dudaba en afear al mismo Garcilaso. ${ }^{17}$ De todas formas, Avalle-Arce se vio obligado a admitir como caso excepcional el comienzo de la propia Galatea, con un homicidio, puñal en mano. En cualquier caso, la evidencia de la milenaria tradición dicta exactamente lo contrario, como le recordó Iventosch en un artículo de tono reivindicativo del año $1974 .{ }^{18}$ La aportación más

\footnotetext{
${ }^{15}$ Alberto Blecua ha trabajado las múltiples deudas que Cervantes contrajo en su obra literaria con la retórica, en "Cervantes y la retórica (Persiles, III, 17)", Lecciones cervantinas, estudios coordinados por Aurora Egido, Zaragoza, Caja de Ahorros y Monte de Piedad de Zaragoza, Aragón y Rioja, 1985. En sus clases y conferencias ha derrochado también abundante y sabia información sin publicar cuyo recuerdo aflora aquí. Por suerte está a punto de aparecer su edición del Quijote de 2005 en Espasa - Calpe, en cuyo extenso prólogo se recogerán estos y otros detalles. Véase también la "Lectura" de Javier Blasco en la citada edición de Crítica del Quijote, t. II, pp. 41-49.

${ }^{16}$ Hacia Cervantes, cito por la edición de 1967, Madrid, Taurus, p. 300.

${ }^{17}$ Véase el estudio de Bienvenido Morros, "La idea de la lírica en las Anotaciones a Garcilaso", Idea de la lírica en el Renacimiento (entre Italia y España), ed. María José Vega y Cesc Esteve, Villagarcía de Arousa (Pontevedra), Seminario de Poética Europea del Renacimiento, Universidad Autónoma de Barcelona, Editorial Mirabel, 2004, pp. 211-229.

18 "Cervantes and Courtly Love: the Grisóstomo-Marcela episode of Don Quijote", Publications of the Modern Language Notes, LXXXIX (1974), pp. 64-76. En donde no se hacía referencia alguna a las consideraciones que respecto al mismo episodio había desarrollado Avalle-Arce años antes, en 1961, en sus Deslindes cervantinos, de contenido renovado y ampliado en Nuevos deslindes cervantinos, Barcelona, Ariel, 1975. Con este y otros reproches se defendió Avalle-Arce en "Cervantes, Grisóstomo, Marcela and Suicide", nota al editor que apareció en Publications of the Modern Language Notes, XCIX (1974), pp. 1.115-1.116. La nota obtuvo una no menos agria réplica de parte de Iventosch en la misma revista, XC (1975), pp. 295-296.
} 
importante de Iventosch es una de las fuentes de la Canción desesperada, de tradición italiana, ${ }^{19}$ que probablemente llega a Cervantes a través de un poema de Cetina ("Canción desesperada y sin concierto, / nacida entre sospechas y temores..."); y también, su coda sobre suicidios bucólicos en donde repasa la tradición desde el Ninfale fiesolano de Boccaccio, Tebaldeo, Antonio Epicuro, Juan del Encina y el amago de suicidio que hay en el Aminta de Tasso. No hará falta recordar aquí que de esta tradición derivan el Carino de Sannazaro y a su vez un Albanio en clave bufa, aportación de nuestro príncipe de los poetas: más atrás, cómo no, resuena la melancólica letanía de los versos menalios de Damón, contrariado por Nisa, anuncio de su inminente intención de regalarle su vida de moribundo arrojándose de cabeza al mar desde la cima de un elevado monte ("praeceps aërii specula de montis in undas/deferar; extremum hoc munus morientis habeto", vv. 5960, Buc. VIII de Virgilio).

La lista dista de ser exhaustiva, de hecho podría completarse, por ejemplo, con las fuentes de principios de siglo que ofrece Raimondo Guarino, aunque el catálogo es a buen seguro muchísimo más amplio. ${ }^{20}$ Baste mencionar aquí que a la altura de 1598, Angelo Ingegneri, prestigioso escenográfo veneciano, aconsejaba evitar en las pastorales los omicidi volontari, eletti per disperazione - tan frecuentes se habían vuelto- y ello porque el "disperato (massimamente per sola cagion d'amore) quando si risolve voler morire, induce più tosto riso che compassione". Y añadía que el personaje que resuelve poner fin a su vida pierde toda la nobleza y el aprecio que se le tendría en caso contrario, por huir de la tristeza en que se encuentra y no tener suficiente ánimo para "resistire alla disgrazia virtuosamente e di vincer con valore la fortuna." 21 Es de notar que ninguna mención a cuestiones teológicas tiene lugar aquí. Y aparte de las objeciones canónicas a un suicidio abiertamente reconocido, respecto de la adecuación de la muerte al universo pastoril, ¿cómo se explicaría si no el lema "Et in Arcadia ego" que Guercino y Poussin hicieron suyo en sus cuadros? ? $^{22}$ La tradición literaria de la muerte por desesperación de amor, que la pastoral dramática explotó por su efectismo sobre las tablas, quedaba así asegurada; si Cervantes decidió reproducir dicha herencia bucólica en el episodio del Quijote con características pastoriles más acusadas fue quizá porque daba la sensación de ser un golpe más de la realidad, aunque para ello hubiera de echar mano, irónica y paradójicamente, de uno de sus motivos literarios más antiguos. Era, por otra parte, otra forma de poner la novela a prueba frente al mundo cotidiano: si los poetas se llenaban la boca del funesto deseo de muerte, Grisóstomo no era menos y la invocaba también, pero lejos de derrochar su artillería en salvas, pagaba su poético desvarío de amor con la vida.

\footnotetext{
${ }^{19}$ Véanse las precisiones de Lapesa en "La descendencia hispano-portuguesa de una canción petrarquesca: de Garcilaso a Camoes y Cervantes", Homenaje a Alonso Zamora Vicente, Madrid, Castalia, 1992, III-2, pp. 131147.

${ }^{20}$ En "Le mimesi di Ruzante. L'attore letterato e la differenza linguistica", artículo destinado a las actas del congreso dedicado al Ruzante "In lingua grossa, in lingua sottil", Padua, Diciembre de 2003, http://www.univaq.it/culturateatrale/materiali/Guarino/ruzante/guarinoruzante.pdf.

${ }^{21}$ En su Della poesia rappresentativa e del modo di rappresentare le favole sceniche, dedicado a Cesare d'Este, ed. Maria Luisa Doglio, Modena, Panini, Istituto di Studi Rinascimentali, 1989, p. 16.

${ }^{22}$ Véase el citado artículo de Panofsky, También Gilbert Higuet, La tradición clásica, I, México, Fondo de Cultura Económica, 1978, p. 284, n. 63.
} 
Por otro lado, las divagaciones de Avalle-Arce sobre la ambivalencia con que Cervantes trata el tema del suicidio siguen siendo válidas: el significado que Ingegneri atribuye al disperato corrobora el sentido más trágico de los dos que aducía el citado crítico del Tesoro de Covarrubias sobre la voz Desesperar. En primer lugar es perder por completo la esperanza. "Deseperarse es matarse de cualquier manera por despecho; pecado contra el espíritu Santo. No se les da a los tales sepultura; queda su memoria infamada y sus bienes confiscados, y lo peor de todo es que van a hacer compañía a Judas. Esto no se entiende de los que estando fuera de juicio lo hicieron, como locos o frenéticos." La otra acepción es simplemente impacientarse, de todos conocida. Cervantes conocía ambos sentidos y en la Galatea, el Quijote y el Persiles alude, en ejemplos de Avalle-Arce, al primero de ellos. ${ }^{23}$

Los versos de la canción no dejan lugar a dudas:

¡Oh en el reino de amor fieros tiranos

celos!, ponedme un hierro en estas manos.

Dame, desdén, una torcida soga (...)

Yo muero, en fin, y porque nunca esperé

buen suceso en la muerte ni en la vida,

pertinaz estaré en mi fantasía. (...)

Diré que la enemiga siempre mía

hermosa el alma como el cuerpo tiene,

y que su olvido de mi culpa nace,

y que en fe de los males que nos hace,

Amor su imperio en justa paz mantiene.

Y con esta opinión y un duro lazo,

acelerando el miserable plazo

a que me han conducido sus desdenes,

ofreceré a los vientos cuerpo y alma,

sin lauro o palma de futuros bienes (...)

$\mathrm{y}$ todos juntos su mortal quebranto

trasladen en mi pecho, y en voz baja

-si ya a un desesperado son debidas-

canten obsequias tristes, doloridas,

al cuerpo, a quien se niegue aun la mortaja.

A juzgar por estos endecasílabos, ${ }^{24}$ Grisóstomo participa activamente en su propia muerte; o en pocas palabras, se quita la vida, y, al parecer, colgándose de un árbol. Puede que de ahí vengan sus deseos de ser enterrado "en el campo, como si fuera moro, y que sea al pie de una peña donde está la fuente del alcornoque," pues un suicida no podría recibir

\footnotetext{
${ }^{23}$ Aduce Avalle-Arce, "varios ejemplos en que [Cervantes] alude evidentemente al suicidio: "Sólo imaginaba que, según le vio triste y melancólico después de la batalla, que no podía creer sino que a desesperarse hubiese ido" (Galatea, III, BAAEE, t.1, p. 37b). "Con justo título puede desesperarse y ahorcarse" (Quijote, I, 25 ibid. p. 315. ) En el Persiles (II, 14; idid., p. 610b) un marinero intenta suicidarse y Persiles comenta: " 'Con la vida se enmiendan y mejoran las malas suertes y con la muerte deseperada no sólo no se acaban y mejoran, pero se empeoran y comienzan de nuevo. Digo esto, compañeros míos, por que no os asombre el suceso que habéis visto deste nuestro desperado.' ", art.cit., p. 195.

${ }^{24}$ Véase el capítulo dedicado a la Canción desesperada en el libro de Arturo Marasso, Cervantes, Buenos Aires, Academia Argentina de las Letras, 1947, donde se analizan las fuentes de dicha composición poética: se recuerdan huellas de Virgilio en la deseperación de Grisóstomo, deudora de la de Dido, así como de la Fedra de Séneca, entre otros ecos clásicos.
} 
cristiana sepultura. Cierto es que hay algunos ecos del rito antiguo en la misteriosa y elocuente oración fúnebre de Ambrosio, como ha recordado Marasso, así como en los pellicos de negra lana que visten los pastores, aunque no en su corona de tejo o de ciprés: el recuerdo es ahora de las pompas con que Eneas ordena solemnizar el primer aniversario de la muerte de Anquises, y ordena a sus compañeros que ciñan sus sienes con ramos: et cingite tempora ramis $(\mathrm{V}, 71)$. El sabor pagano de esta escena es aun así muy fugaz si la comparamos a los sobrenaturales efectos de la ceremonia oficiada por Telesio en el Valle de los Cipreses del último libro de la Galatea: Cervantes ha restringido aquí notablemente su descripción y su maravilla en aras de nuevo de la verosimilitud, pero no ha querido tampoco renunciar del todo al incienso de su decorado clásico pues es cita obligada sobre todo desde la Arcadia de Sannazaro, con su escena en torno a la tumba de Androgeo (Prosa V) y las paganizantes exequias (Prosa XI) de Massilia, madre de Ergasto, amenizadas a su vez gracias al ejemplo de los juegos fúnebres por el padre de Eneas (V, 42-71). Esta arraigada tradición explica que al triste episodio del Quijote le alcancen todavía algunas sombras de las honras fúnebres oficiadas por Telesio: en los tocados de los amigos de Grisóstomo hay un recuerdo de la escena en que el sabio se acerca a un ciprés y cortando algunas ramas, "hizo de ellas una funesta guirnalda con que coronó sus blancas y veneradas sienes, haciendo señal a los demás que lo mesmo hiciesen"; o cuando los pastores depositan en el suelo las andas "cubiertas de mucha diversidad de flores y ramos", con el juvenil cuerpo de Grisóstomo inerme, en el "maravilloso silencio" que todos guardan hay un eco muy reconocible del "maravilloso y sosegado silencio" que precede en la Galatea a la Elegía a Meliso, ${ }^{25}$ y más lejos aún, de la quietud y el "silenzio" de las selvas en torno al sepulcro de Massilia. ${ }^{26}$ De todas formas, regresando a la discusión sobre el suicidio de Grisóstomo, y al margen de las resonancias paganas de su funeral, la posibilidad de deducir que se había quitado la vida porque no iba a ser enterrado como buen cristiano había quedado de hecho desmentida desde el principio por "los abades del pueblo" que afirmaban que sus últimos deseos "no se han de cumplir ni es bien que se cumplan, porque parecen de gentiles”. ¿En qué quedamos? No es extraño que al analizar este y otros detalles contradictorios -quizá aumentados porque la canción se compuso con antelación y era ajena a la novela- Avalle-Arce concluyera que la "ambigüedad del título de la Canción desesperada se aumenta y se proyecta sobre todo el episodio." Así que una vez más, Cervantes deja las puertas abiertas a distintas interpretaciones y evita tomar partido por una sola de ellas.

Anotaré aquí, a título de curiosidad, que la historia de Marcela y Grisóstomo, desgajada del resto de la obra, fue el segundo texto del Quijote que se vertió al francés (en edición bilingüe, una práctica muy habitual en la traducción de novelas sentimentales como la Cárcel de amor), y madrugó tanto que incluso se adelantó a la temprana traducción

\footnotetext{
${ }^{25}$ Recuerdo de la égloga funeral escrita en tercetos esdrújulos de La Arcadia, donde dos pastores van descubriendo sobre las cortezas de los árboles los epigramas que Meliseo escribió en memoria de Fillide: la situación se inspiraba a su vez en una de las églogas de Calpurnio, que fue fuente a su vez para la que escribió Pontano (cuyo seudónimo era Meliseus) por la muerte de su querida esposa, y de la cual, en la égloga fúnebre del napolitano, se rememoran algunos versos traduciéndolos.

26 "...non si sentivano più voci di cani, nè di fiere, ne di ucelli: le foglie sovra gli alberi non si moveano: non spirava vento alcuno: solamente nel cielo in quel silenzio si potea vedere alcuna stella o scintillare o cadere...”, ed. de Enrico Carrara de las Opere di Jacopo Sannazaro, Turín, Unione Tipografico-Editrice Torinese, 1956, p. 193.
} 
completa de Thomas Shelton en 1612, que inspiraría a Shakespeare su History of Cardennio: $:^{27}$ me refiero a una extraña obra titulada Homicidio de la fidelidad y defensa del honor, aparecida en París, por Jean Richer, en $1609,{ }^{28}$ que todavía seguía agradando al público en 1715, cuando Josue Steenhouwer y Hermanus Uytwerf la volvieron poner a la venta en Amsterdam, ligeramente reelaborada, y ofreciendo sólo el texto francés como primer relato de Le desespoir amoureux avec les nouvelles visions de Don Quichotte. Histoire espagnole. ${ }^{29}$ El lector francés, que difícilmente podría valorar las gracias tan desparpajadas como castizas de los diálogos entre el hidalgo y su escudero, se inclinó así enseguida por los relatos intercalados, como corrobora que un año antes (1608) apareciera en las prensas parisinas una traducción del Curioso impertinente, mientras en España a Cervantes le silbaban los oídos. Una "de las tachas que le ponen" a la historia del hidalgo manchego, comentará él mismo algo más tarde, en el Quijote de 1615, creando así un genial juego de espejos que todavía hoy sigue dando pie a nuevas y brillantísimas obras narrativas, "es que su autor puso en ella una novela intitulada El Curioso impertinente, no por mala ni mal razonada, sino por no ser de aquel lugar, ni tiene que ver con la historia de su merced del señor don Quijote" (II, 3). Son muchas las razones por las que en Francia, en cambio, se apreciarán tanto las novelas breves españolas; tan solo mencionaré aquí una curiosa que aducía Charles Sorel en su Bibliothèque Françoise, de 1664: a diferencia de la tradición picante de las novelitas escritas a la sombra de Boccaccio, estas narraciones castellanas "les dames les pouvoient lire sans apprehension."

De hecho, la versión francesa de la historia de Marcela y Grisóstomo se aproxima más a una adaptación, en donde lo primero que llama la atención es el nuevo nombre de sus protagonistas, quizá por dificultades en la pronunciación de alguno de los originales en francés: Grisóstomo pasa a llamarse Philidon; Marcela, primero Marcelle, después Floride $^{31}$; Ambrosio, Daphnis. El relato está completamente desprovisto, además, de las opiniones contrapunteadas de don Quijote y Sancho, así como los comentarios rústicos de los cabreros o de los amigos de Grisóstomo que acuden a sus funerales. ${ }^{32}$ La narratio deja de ser perspectivística, azarosa, y por el contrario, un narrador omnisciente empieza a relatar $a b$ ovo, sin alusión de momento a la muerte del protagonista, concentrándose en los

\footnotetext{
${ }^{27}$ Parece que solo la primera parte sería del gran dramaturgo, y de Fletcher, la segunda. Véase un resumen del estado de la cuestión en España en Shakespeare de Pedro J. Duque, Universidad de Deusto-Universidad de León, 1991, pp. 212-215.

${ }^{28}$ Le meurtre de la fidelité et la defense de l'honneur. Où est racontée la triste et pitoyable avanture du berger Philidon et les raisons de la belle et chaste Marcelle accusée de sa mort. Avec un discours de Don Quixote de l'excellence des armes sur les lettres, Paris, Jean Richer, 1609.

${ }^{29}$ El editor comentaba en el Advertissement: "Nous en sommes redevables aux Ecrivains Espagnols que je n'ai fait que traduire, \& sur tout à l'Auteur de l'Histoire de la belle Floride \& du Berger Philidon, avec les visions de Don Quichotte, dans son Livre intitulé, Homicidio de la fidelitad (sic), y la defensa del honor, imprimé a Paris, l'an mil six cens neuf, chez Jean Richer, et connu en sa Langue originale plus d'un siècle avant que Miquel Cervantes, qui a donné le célèbre Roman de Don Quichotte, ait éte au monde." La última frase es a todas luces un error.

${ }^{30}$ Ob. cit., Paris, Compagnie des libraires du Palais, 1664, pp. 178-179.

${ }^{31}$ Floride en la versión tardía publicada en 1715; en cambio, en la primera traducción bilingüe de 1609 , se mantiene "Marcelle".

${ }^{32}$ Como, por ejemplo, en este exhorto a continuar el relato por parte del hidalgo: "Así es verdad -dijo don Quijote-, y proseguid adelante, que el cuento es muy bueno, y vos, buen Pedro, le contáis con muy buena gracia." $(\mathrm{I}, 12)$.
} 
orígenes de Floride y Philidon. Algunos detalles más o menos superfluos quedan así suprimidos, como el sacerdocio del tío de Marcela, "qui étoit", de forma más genérica y exagerada, "très-riche \& très-honnête homme" (en la versión de 1715); pero otros pormenores fundamentales en la narración cervantina también desaparecen, como los juicios de valor que sobre Marcela se van diseminando en el episodio: se esfuma la mención a "aquella endiablada moza llamada Marcela" puesta en boca del mozo encargado de traer las provisiones; ninguna traducción se ofrece a la "pastora homicida" que menciona uno de los caballeros acompañantes de Vivaldo; y el sayagués del cabrero "hételo aquí, cuando no me cato, que remanece un día la melindrosa Marcela hecha pastora", se transforma en la versión española de 1609 en el doblete con alabanza "gentil y melindrosa", y de ahí a la suavización francesa de la misma edición en "la gentille \& delicate Marcelle"; la versión de 1715 vuelve a la singularidad ya directamente elogiosa de "la charmante Floride", propia de un narrador refinado y omnisciente que mira desde fuera los desaguisados ocasionados por su gélida belleza. Otros pormenores afloran en la traducción dieciochesca por vez primera, como la descripción de la bella Floride, ${ }^{33}$ completamente ausente en el original cervantino y en la primera versión bilingüe.

El elogio de Ambrosio, con el difunto de cuerpo presente, se convierte en una presentación de Philidon construida con las palabras del amigo extraídas de su fúnebre contexto. Y a continuación aparece don Quijote por primera vez en el texto francés, como alguien ya muy célebre ("Le fameux, \& par imagination le vaillant \& courageux Chevalier errant Don Quichotte") $)^{34}$ que muy pronto entabla conversación con Vivaldo (capítulo 13 del original), salvo cuando su análisis de la caballería andante se adentra en la supuesta "nobleza" de Dulcinea del Toboso, y en guasa Vivaldo se atribuye el linaje de los Cachopines de Laredo, toscos ancestros que también se agenciaba para darse postín el pajecico de la Diana de Montemayor. El pasaje fue hábilmente omitido por el adaptador de la versión de 1609, pues debió considerar con razón que al traductor le resultaría incomprensible; así que ni corto ni perezoso continuó la intervención quijotesca con el discurso de las armas y las letras (I, 37 del original), seguido con cierta fidelidad hasta llegar al párrafo con los denuestos contra las armas de fuego, que termina, de acuerdo con la misma labor de recorte y pega, con el discurso del buen caballero andante que Don Quijote pronunciaba en tercera persona a instancias del bueno de Sancho en el capítulo 21. Aquí se transforma, en cambio, en un ejercicio de autocomplacencia extenuante-siempre en primera persona-, poco cortés con la inteligencia del lector, tan presente en cambio en las constantes e irónicas acotaciones cervantinas. ${ }^{35}$ El discurso de Floride que cierra el relato contiene, además, notas de emoción fruto de la cosecha del traductor de 1715 de las que carece voluntariamente la novelita española, a buen seguro porque al traductor debió sorprenderle desagradablemente la ausencia en labios de Marcela de algún comentario compasivo sobre la desgracia de Grisóstomo ante el auditorio de compungidos seres

\footnotetext{
33 "Elle avoit les cheveux noirs, le teinte blanc, des grands yeux perçans jusque'au fond de l'ame, un sourire gracieux, les plus belles dents du monde, des levres couloeur de corail; sa gorge, ses mains \& sa taille relevoient encore tous ces avantages de la nature...", p. 4.

${ }^{34}$ Célebre a esas tempranas fechas para el adaptador castellano de la versión biligüe, que se refiere a él como el "famoso y por imaginación valiente y esforçado Cauallero andante Don Quixote de la Mancha", p. 22.

${ }^{35}$ Por citar un ejemplo al azar: "Les nouvelles de mon départ tireront des soupirs \& des sanglots du plus profond de son coeur, suivi d'une défaillance \& d'un évanouïssement...", p. 25
} 
queridos que velaban su cuerpo, y quiso subsanar por su cuenta una carencia del original que debió juzgar injustificable. Pero el discurso de Marcela, lejos de estar orientado a pedir disculpas o hacerse humildemente perdonar, quiere ante todo persuadir de su inocencia y causar la admiración -y la indiferencia- necesarias para recuperar la libertad y volver a alzar el vuelo; su falta de empatía, así como de compasión por la desgracia que directa o indirectamente ha provocado, era la eficacísima y silente forma en que Cervantes se proponía hacer ostensible el apartamiento -pero también la marginación- de Marcela con respecto al mundo. ${ }^{36}$

Y ya para terminar, una breve consideración final: qué figura tan improbable es la de Marcela. Tanto, de hecho, como Alonso Quijano, hidalgo de vida anónima en una aldea perdida de la Mancha, alter ego del cincuentón ninguneado que era su autor a la altura de 1605 , quien en el ocaso de su vida -cuya esperanza era por entonces mucho más cortadecidió vivir sus sueños. Marcela también desea ser y es libre, pero en su intento -conseguido- de serlo, su dialéctica frente a la incomprensión, la animadversión, las zancadillas morales que se le tienden al paso, está muy lejos de producir risa o compasión: no nos conmueve, y aunque termine por ganarse nuestra admiración y respeto, ello es siempre en una fría distancia ("Fuego soy apartado y espada puesta lejos"). ${ }^{37}$ Desprovista de teologías, su femineidad es de carácter espiritual, y la convierte en una casta labradora consagrada a Diana, una Gelasia ya no cruel, una Anajárete sin castigo, o una suerte de monja laica: "Tienen mis deseos por término estas montañas, y si de aquí salen es a contemplar la hermosura del cielo, pasos con que camina el alma a su morada primera." 38 Pero también es cierto que Marcela no es más que una mujer, y si la miramos y escuchamos sin prisas resulta fácil adivinar tras su escorzo, entre bastidores, al hombre que la concibió, mientras criaba a su sobrina e hija naturales y soportaba la mancilla del menosprecio hacia sus hermanas, las "Cervantas", a quienes no por eso negaba el cobijo. Tras la impecable y modernísima defensa de la libertad femenina, adivinamos así el pálpito humano, el sufrimiento y la vergüenza transformados una vez más por obra y arte del creador de don

\footnotetext{
36 "Quoique la belle Floride fut naturellement in sensible, \& qu'elle eut toujours fait gloire de l'être, elle ne put s'empêcher d'être touchée d'un spetacle si lugubre. Elle laissa malgré elle couler quelques larmes; \& regardant Daphnis avec une pitié mêlée de colere, Que vous êtes cruel dans vos reproches, lui dit-elle, violent Berger, \& que les hommes sont in justes! Je plains la mort du pauvre Philidon...", p. 31. Véase también la n. 30.

${ }^{37}$ Sobre los ecos pitagóricos de estas palabras, véase el libro ya citado de Arturo Marasso, pp. 48-49, estudio en el que también se compara la belleza selvática de Marcela con la fiereza de Camila en la Eneida. Por lo que respecta al discurso distante y frío de Marcela, Thomas R. Hart y Steven Rendall (mientras corrigen a Mary Mackey, "Rhetoric and Characterization in Don Quijote", Hispanic Review, 42 (1974), pp. 51-66) sugieren, por su parte, que Marcela sólo consigue apelar al entendimiento de su audiencia (los amigos de Grisóstomo), pero incluso hallándose éste de cuerpo presente, desdeña el pathos y ethos en un discurso de razonamientos impecables exentos de toda emoción (en ningún momento da muestras de compasión por el infortunio de su enamorado). La circunstancia en que se pronuncia y el público al que se dirige ("the sheperds are not prepared to render a judgment sololy on rational grounds") lo convierten en tan inadecuado como el discurso de la Edad de Oro de don Quijote, sobrecargado de figurae verborum dedicadas a los cabreros. Véase "Marcela's Adress to the Shepherds", Hispanic Review, 46 (1978), pp. 287-298.

${ }^{38}$ Hay aquí posibles ecos de la Oda a la noche serena de Fray Luis de León ("Morada de grandeza / templo de claridad y hermosura, / mi alma que a tu alteza nació, ¿qué desventura / la tiene en esta cárcel, baja, escura?). Véase Stanislav Zimic en "La muerte de amores de Grisóstomo", Los cuentos y las novelas del Quijote, Biblioteca Aurea Hispánica, Universidad de Navarra, 2003, pp. 39-58.
} 
Quijote, en generosidad y tolerancia. "Admirable retórico Cervantes", escribía con razón Alberto Blecua, "pero, sobre todo, admirable ser humano."39

39 "Cervantes y la retórica...", p. 147. 